\title{
New fines pose financial catch-22 for Ontario long-term care
}

\author{
Cite as: CMAJ 2018 May 22;190:E630-1. doi: 10.1503/cmaj.109-5600
}

Posted on cmajnews.com on May 2, 2018.

\begin{abstract}
ncreased scrutiny of Ontario's longterm care sector appears to be improving quality of care, but new enforcement measures could make it harder for some facilities to meet government expectations.
\end{abstract}

Starting in January 2019, long-term care homes that fail to follow orders to comply with provincial quality standards will face fines up to $\$ 10000$ each time those orders are reissued, plus $\$ 500$ for each additional inspection required until the problem is resolved. The minister of health and long-term care will have new powers to suspend an operator's licence until concerns are addressed. In the most egregious cases, the government can prosecute operators and fine them up to $\$ 200000$ for a first offence and $\$ 500000$ for subsequent offences.

Previously, the province had few options for holding long-term care operators accountable, short of revoking their licences and shuttering homes. "That's a very extreme action and it's hard for everybody," particularly the residents who had to be moved, said Karen Simpson, director of Ontario's long-term care inspections branch. The fines provide a more flexible enforcement tool, she explained at the Advancing Senior Care Conference, held recently in Toronto.

Operators of long-term care homes say the fines may create a vicious cycle where poor performers will be left with fewer resources to correct problems. "It's a catch-22," said Lisa Levin, CEO of AdvantAge Ontario, an association representing nonprofit homes. Most compliance issues are linked to underfunding and understaffing of homes, she explained. To fix those root problems, "we need to make sure the resources put into the sector are used for care wherever possible."

Because the funding formula for homes is based on resident acuity, there is already an unintended disincentive to improve quality of care, said Levin. "As resident outcomes improve, the funding goes down."

According to Simpson, the quality of long-term care in Ontario has improved "year after year" with increasing scrutiny of the sector. New data presented by inspection officials show the average number of written warnings issued per inspection dropped from 12 in 2014 to seven in 2017, while the average number of compliance orders dropped from two to less than one.
Even so, a small percentage of homes repeatedly fail to address care and safety issues. Ninety-one homes, about $14 \%$ of Ontario's total, did not comply with at least one order last year. Forty-six percent of those orders were related to high-risk issues, a category that includes medication incidents, alleged abuse, and infection prevention and control. One order related to a "critical risk." Most homes complied after the government reissued orders, suggesting ability to comply wasn't a major barrier, noted Simpson. "It just requires focused attention."

Others at the conference disagreed, arguing that many of the issues flagged by provincial inspectors are caused by factors outside a home's control. For example,

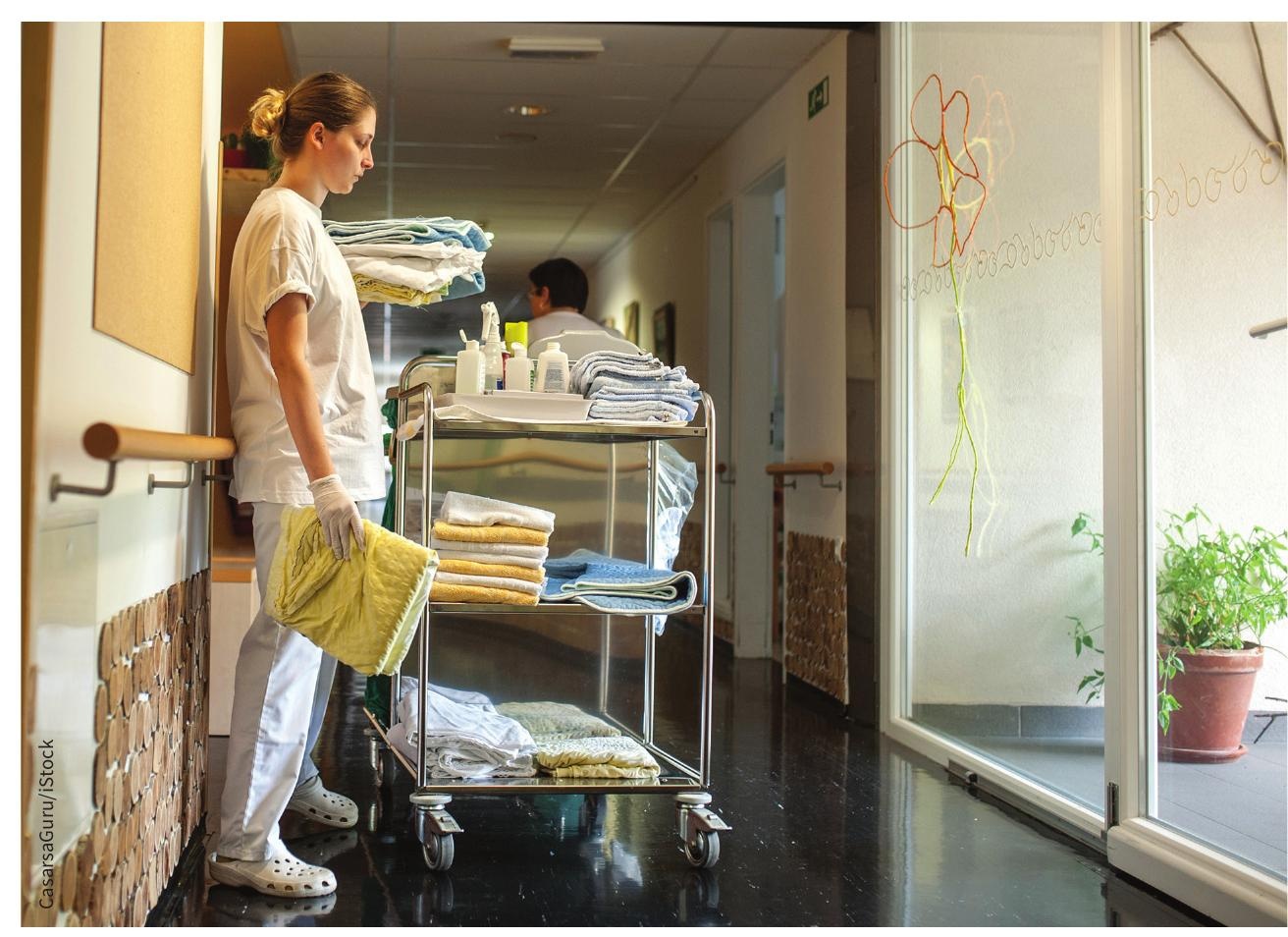

Financial penalties may exacerbate problems caused by staffing and resource shortages, say longterm care operators. 
new certification requirements for personal support workers have exacerbated staffing shortages. Some homes are also struggling to ensure there's a registered nurse onsite 24/7 because they don't have the budget to hire redundant staff to cover sick days, and the ministry considers them noncompliant if they use temporary staff.
Simpson said the ministry is aware of these pressures, but the rules exist for a reason. "We've been in a few homes lately where they had [staff] who weren't qualified, with some pretty serious negative outcomes."

The Liberal government has promised new funding to train personal support workers and cover the cost of one additional registered nurse in every home. But with a provincial election on the horizon, there are no guarantees, said Levin. "We'll have to see if they get into power, and if not, what another government will do."

Lauren Vogel, CMAJ 